\section{Summary of: Acceptability of fissure sealants from the child's perspective}

\author{
A. G. Morgan, ${ }^{* 1}$ A. K. Madahar ${ }^{2}$ and C. Deery ${ }^{3}$
}

\section{FULL PAPER DETAILS}

${ }^{1}$ Consultant in Paediatric Dentistry, Department of Paediatric Dentistry, Charles Clifford Dental Hospital, Wellesley Road, Sheffield, S10 2SZ; ${ }^{\text {SSpeciality }}$ Registrar in Orthodontics, Royal London Dental Hospital, Whitechapel, London, E1 1BB; ${ }^{3}$ Professor/ Honorary Consultant in Paediatric Dentistry, Department of Paediatric Dentistry, Charles Clifford Dental Hospital, Wellesley Road, Sheffield, S10 2 SZ

${ }^{*}$ Correspondence to: Miss Annie Morgan Email:Annie.Morgan@sth.nhs.uk Online article number E2 Refereed Paper - accepted 24 February 2014 DOI: 10.1038/sj.bdj.2014.553 •British Dental Journal 2014; 217: E2

\begin{abstract}
Aim To seek children's opinions about the acceptability of resin fissure sealant placement. Study design Service evaluation using a child-centred questionnaire issued to a prospective sample of consecutive hospital patients. Method Questionnaires were issued to children, aged 3 to 16 years, immediately after resin fissure sealant placement in the Paediatric Dentistry Department in Sheffield. Participants used a three-point faces scale for positive, neutral and negative responses, arranged as a Likert scale with minimal text, to rate their treatment experiences and satisfaction with the dental visit. Results Two hundred questionnaires were returned. Overall, $96 \%(n=191)$ recorded a positive or neutral response for the ease at which they coped with the procedure, with most children positive about having fissure sealants placed again $(66 \% ; n=132)$. Further analysis demonstrated that children who had fissure sealants on a previous occasion found them easier than those having them for the first time ( $p<0.05$, chi-squared test). Almost half of all participants where ambivalent about the taste and feeling (46\%; $n=92$ and $55 \% ; n=110$ respectively). The vast majority of children were satisfied with the explanations provided by their operator. Conclusion Most participants found having resin fissure sealants placed an overall acceptable procedure, with patient acceptance improving with increased treatment experience.
\end{abstract}

\section{EDITOR'S SUMMARY}

Recently, I was party to a conversation between my parents and my mum's cousins about how best to care for my 90-yearold great-aunt, Teresa. You can imagine the conversation - should we move her to a care home? She would be more comfortable there. But maybe moving her from home would be too much disruption for her? And so it went on until my dad asked the question: 'What does Teresa want?' They all stopped short. Aunty Teresa is generally fairly 'with it', though physically she is very frail. They hadn't asked her. It's not as if they didn't care enough about her or they were only thinking of themselves. On the contrary, these are the people that care about her and for her the most. They were worried about her and wanted the best for her. They just hadn't thought to ask her what she wanted.

When it comes to vulnerable people, this is often what happens. This applies both to vulnerable adults, like my Aunty Teresa, and to children. Traditionally, in the case of paediatric dentistry, researchers would assess the impact of a treatment or service by asking an adult, usually a parent, as a proxy for the young person.
That's fine. It's important to hear what the carers think and sometimes they might be able to articulate their feedback more understandably than the young person. But it does mean that little is known about what the paediatric patients themselves think about dental treatments, and in the case of this paper particularly, what they think about fissure sealants.

Health policy in this regard is changing. For example, recent UK health policies, such as the Department of Health's 2010 paper Achieving equity and excellence for children, are making it a priority for healthcare providers to listen to children and young people about their treatment and opinion of services offered. Policy is also moving to ensure that children have some involvement in the decision-making about their own care.

So what do children think about fissure sealants? The authors report that the majority of young patients questioned did not mind having fissure sealants placed. Good to know. Arguably what was even more useful to determine was why the minority did mind. What was it about this simple procedure that troubled them? The taste it seems. Well, that's useful to know.
However, the authors point out that there were potential confounding factors, for example for some participants toothpaste was smeared over recently placed sealants. It seems that further work is needed here - we need to find out what particular taste they didn't like: was it the mouthrinse, the sealant, the toothpaste, the gloves perhaps? But immediately we have a result because child-centred research is a bit like space exploration, we may find answers to questions we hadn't even thought to ask before.

The full paper can be accessed from the $B D J$ website (www.bdj.co.uk), under 'Research' in the table of contents for Volume 217 issue 1.

\section{Ruth Doherty} Managing Editor

1. Department of Health. Achieving Equity and Excellence for Children. Gateway reference 14788. 2010. Online paper available at https://www.gov.uk/ government/publications/achieving-equity-andexcellence-for-children (accessed July 2014).

DOI: 10.1038/sj.bdj.2014.576 


\section{TO ACCESS THE BDJ WEBSITE TO READ THE FULL PAPER}

- BDA Members should go to www.bda.org.

- Click the 'login' button on the right-hand side and enter your BDA login details.

- Once you have logged in click the 'BDJ' tab to transfer to the BDJ website with full access.

IF YOUR LOGIN DETAILS DO NOT WORK:

- Get a password reminder: go to www.bda.org, click the login button on the right-hand side and then click the forgotten password link.

- Use a recommended browser: we recommend Microsoft Internet Explorer or Mozilla Firefox.

- Ensure that the security settings on your browser are set to recommended levels.

IF YOU HAVE NOT YET SIGNED UP TO USE THE BDA WEBSITE:

- Go to www.bda.org/getstarted for information on how to start using the BDA website.

\section{COMMENTARY}

So children don't mind having fissure sealants placed. Well, we knew that anyway, didn't we? Actually, we didn't. Our clinical experience may tell us that the majority of children take fissure sealing in their stride, but this is the first study of how children feel about the process of having sealants placed, as reported by themselves. Hardly any studies in paediatric dentistry have reported on the patients' perspective of treatment and for the very few that have done so the results can be surprising.

Fissure sealing remains a cornerstone of an effective caries preventive programme and is supported by an excellent evidence base. In fact, the recently revised Scottish Intercollegiate Guidelines Network (SIGN) guidance on dental interventions to prevent caries in children ${ }^{2}$ has taken the bold step of recommending the placing of resin-based sealants on the permanent molars of all children in Scotland and not just those at increased caries risk. An uncomfortable truth is that there is probably little excuse for a child under the regular care of an oral health professional to ever develop new caries in pits or fissures. Fissure sealants, properly placed and properly maintained as they wear away, for as long as the patient remains at increased risk of caries, will prevent cavities forming.

This study is not definitive; the fact that only $66 \%$ of the children were positive about having sealants placed in the future needs exploring further, as does the fact that $26 \%$ were negative about the taste. Placing a smear of toothpaste on the newly placed sealant to help disguise the taste was a novel idea, to me at least, but might wiping off the air-inhibited surface layer of unpolymerised resin with one of the cotton wool rolls used for tooth isolation while removing it from the mouth (as recommended by other guidance; www.sdcep.org.uk), prove just as effective, with less mess? It would be good to look at this.

This excellent study, on patients' perceptions of the treatment we provide, is timely and relevant. With fissure sealants we have a caries preventive intervention with a 'Triple A' evidence base rating, ${ }^{3}$ and, with this paper, proven acceptability to children; so why do only $25 \%$ of 12 -year-olds have evidence of sealants, when a third of them have dental decay? Now that's a question to be answered.

\section{Dr Dafydd Evans,}

Senior Lecturer/Hon Consultant in

Paediatric Dentistry

Dundee Dental Hospital \& School

1. Santamaria R M, Innes N P, Machiulskiene V Evans D J, Alkilzy M, Splieth C H. Acceptability of different caries management methods for primary molars in a RCT. Int J Paediatr Dent 2014; DOI: 10.1111/ipd.12097.

2. Scottish Intercollegiate Guidelines Network. Dental interventions to prevent caries in children. Edinburgh: SIGN, 2014

3. Ahovuo-Saloranta A, Forss H, Walsh T et al. Sealants for preventing dental decay in the permanent teeth. Cochrane Database Syst Rev 2013, 3: CD001830.

\section{IN BRIEF}

- Stresses the need to understand children's opinions about the acceptability of resin fissure sealant placement.

- Highlights that children who had fissure sealants on a previous occasion found them easier than those having them for the first time.

- Suggests most participants find having resin fissure sealants placed an overall acceptable procedure.

\section{AUTHOR QUESTIONS AND ANSWERS}

1. Why did you undertake this research?

There is a wealth of scientific evidence available to support the use of fissure sealants to prevent caries development and to stop caries progression. Consequently, their use has been recommended in a number of clinical guidelines. To put it bluntly, fissure sealants work to stop caries. There is an increasing recognition that the opinions of children and young people about their dental treatment and service experiences should be valued and that support with age-appropriate information is provided for them so they can be actively involved in decision-making about their own care. Surprisingly, children have not been asked to give their thoughts and views on fissure sealants before. It is hoped that the findings of the study will contribute to improved understanding and promote better communication with young patients.

\section{What would you like to do next in this} area to follow on from this work?

The School of Clinical Dentistry in Sheffield supports a multi-disciplinary team of researchers that aim to improve the oral health and treatment experiences of children and young people by giving them an active voice in relation to their oral health. This project demonstrates that child-centred research methods can be adapted to facilitate children's participation in service reviews. It is hoped that the findings of this evaluation may be of interest to manufacturers of dental materials, and offer encouragement to consider children's preferences for taste during the development of new products. 